\title{
Strategies to Inform Allocation of Stockpiled Ventilators to Healthcare Facilities During a Pandemic
}

\author{
Lisa M. Koonin, Satish Pillai, Emily B. Kahn, Danielle Moulia, and Anita Patel
}

During a severe pandemic, especially one causing respiratory illness, many people may require mechanical ventilation. Depending on the extent of the outbreak, there may be insufficient capacity to provide ventilator support to all of those in need. As part of a larger conceptual framework for determining need for and allocation of ventilators during a public health emergency, this article focuses on the strategies to assist state and local planners to allocate stockpiled ventilators to healthcare facilities during a pandemic, accounting for critical factors in facilities' ability to make use of additional ventilators. These strategies include actions both in the pre-pandemic and intra-pandemic stages. As a part of pandemic preparedness, public health officials should identify and query healthcare facilities in their jurisdiction that currently care for critically ill patients on mechanical ventilation to determine existing inventory of these devices and facilities' ability to absorb additional ventilators. Facilities must have sufficient staff, space, equipment, and supplies to utilize allocated ventilators adequately. At the time of an event, jurisdictions will need to verify and update information on facilities' capacity prior to making allocation decisions. Allocation of scarce life-saving resources during a pandemic should consider ethical principles to inform state and local plans for allocation of ventilators. In addition to ethical principles, decisions should be informed by assessment of need, determination of facilities' ability to use additional ventilators, and facilities' capacity to ensure access to ventilators for vulnerable populations (eg, rural, inner city, and uninsured and underinsured individuals) or high-risk populations that may be more susceptible to illness.

Keywords: Public health preparedness/response, Ventilator, Allocation, Pandemic, COVID-19

Lisa M. Koonin, DrPH, MN, MPH, is with Health Preparedness Partners, LLC, a subcontractor of General Dynamics Information Technology (GDIT); Danielle Moulia, MPH, is a Public Health Scientist with General Dynamics Information Technology (GDIT); and Anita Patel, PharmD, MS, is Senior Advisor, Pandemic Medical Care and Countermeasures Lead; all in the Influenza Coordination Unit, National Center for Immunization and Respiratory Diseases (NCIRD), Centers for Disease Control and Prevention (CDC), Atlanta, GA. Satish Pillai, MD, MPH, MS, is CDR, US Public Health Service, and Deputy Director, Division of Preparedness and Emerging Infections; and Emily B. Kahn, PhD, MPH, MA, is Senior Epidemiologist/Modeler, Division of Preparedness and Emerging Infections; both in the National Center for Emerging and Zoonotic Infectious Diseases, CDC, Atlanta. The findings and conclusions in this article are those of the authors and do not necessarily represent the official position of the US Centers for Disease Control and Prevention.

(C) Lisa M. Koonin et al., 2020; Published by Mary Ann Liebert, Inc. This Open Access article is distributed under the terms of the Creative Commons License (http://creativecommons.org//licenses/by/4.0), which permits unrestricted use, distribution, and reproduction in any medium, provided the original work is properly credited. 
$\mathrm{D}$ URING A PANDEMIC caused by respiratory pathogens, such as influenza or SARS-CoV-2 (the virus that causes coronavirus disease 2019, or COVID-19), large numbers of people in the United States may require critical care that includes mechanical ventilation, resulting in a surge on hospitals and increased demand for ventilation equipment. Although the current supply of approximately 62,000* ventilators in US acute-care hospitals would likely be adequate to support patient care needs during a pandemic with mild to moderate severity (similar to the 2009 $\mathrm{H} 1 \mathrm{~N} 1$ pandemic), a pandemic with greater severity would probably result in many more patients requiring ventilatory support. ${ }^{1}$ In this severe scenario, there will likely be insufficient capacity to ventilate all those who need this treatment.

Assuming that ventilators would be effective in reducing morbidity and mortality during a future severe pandemic, researchers estimate that approximately 35,000 to 60,500 additional ventilators will be needed. ${ }^{2}$ To support this need, scientists estimate that with robust planning, if US hospitals could increase space and the number of trained and qualified staff to care for ventilated patients during a pandemic, approximately 26,200 to 52,400 additional patients could be ventilated at the peak of a pandemic. ${ }^{3}$ Another study of more than 4,400 hospitals found a significant increase in the number of adult intensive care beds between 2009 and 2011, but this growth was seen mostly in large urban teaching facilities, rather than in rural areas or smaller, less-resourced hospitals, which often serve residents with little or no other access to care. ${ }^{4}$ In addition, there has been an increase in the number of rural hospitals closing each year. ${ }^{5}$

During a public health emergency, federal, state, or local stockpiled ventilators should be deployed in a way that optimizes the effectiveness, efficiency, and equity of this scarce resource. ${ }^{6}$ For over a decade, policymakers and researchers have explored the pros and cons of stockpiling mechanical ventilators in hospitals and other locations. ${ }^{7,8}$ Currently, caches of ventilators are held in reserve in healthcare facilities (largely acute-care hospitals) and in public health stockpiles at the federal, state, and local levels. ${ }^{1,9}$

In addition to having ventilator equipment and ancillary supplies, it is critical for healthcare facilities to have sufficient staff and space to care for as many patients as possible who require ventilation. ${ }^{10,11}$ Legal experts have advised that hospitals, public health entities, and clinicians have an obligation to develop comprehensive, vetted plans for mass casualty incidents involving large numbers of critically ill patients. ${ }^{12}$ Considering these critical factors (ie, sufficient staff, supplies, and space), jurisdictions should plan for how

*This estimate was produced in 2010; more recent estimates are not available. Therefore, this number may not accurately reflect the number of full-featured mechanical ventilators currently in US acute-care hospitals. they would allocate stockpiled ventilators to their relevant healthcare facilities. Researchers have proposed that allocation decisions for a limited supply of stockpiled ventilators to healthcare facilities should not use a pro-rata or "first come-first served" model, but rather they should base allocation on a detailed assessment of facilities' capacity to absorb and use additional ventilators ${ }^{3}$ and to "ensure the efficient, effective, and ethical distribution of stockpiled ventilators" to facilities that can best use them during an emergency. ${ }^{6}$

During a public health emergency, the expectation is for facilities to first use ventilators and ancillary supplies that they have on site (or stored elsewhere); then, if needed, facilities may request support from state or local health departments. If state and local health departments are unable to meet the demand, additional requests for federal stockpiles may be made. If additional ventilators are available from state or federal resources, health departments would be responsible for allocation and deployment to the facilities that can demonstrate they can effectively use them in their jurisdiction.

In 2015, as part of a Pandemic Influenza Readiness Assessment exercise, the Centers for Disease Control and Prevention (CDC) assessed all Public Health Emergency Preparedness jurisdictions $(n=62)$ to ask about their readiness to respond to a pandemic. Within the Medical Countermeasures Module, jurisdictions were asked to identify the key considerations they would use to determine ventilator allocation to hospitals during a pandemic. Of the 62 jurisdictions queried, 57 (92\%) responded. Several key findings from the response included that (1) almost two-thirds $(65 \%)$ of the jurisdictions had conducted a hospital-based assessment between 2010 and 2014 to determine their mechanical ventilation capabilities, and (2) 30 (48\%) jurisdictions (in aggregate covering $46.4 \%$ of the US population at the time) had not determined when or how they would train healthcare systems to operate ventilators from stockpiles. ${ }^{\dagger}$

In addition, jurisdictions were asked about the key parameters that they would consider when evaluating to which facility they would allocate stockpiled ventilators (Figure 1). The most frequent parameter cited was the availability of trained and qualified staff, although this item as well as the number of ICU beds and availability of sufficient equipment and space were all cited by more than $70 \%$ of jurisdictions.

Patients who need mechanical ventilation will be critically ill and will require trained clinicians to provide comprehensive intensive care. The ability to absorb additional ventilators will depend on having sufficient trained and qualified staff to operate ventilators and care for patients, as well as adequate bed space, and availability of essential equipment and supplies needed to care for critically ill

\footnotetext{
$\bar{\dagger}$ Unpublished data, Centers for Disease Control and Prevention.
} 


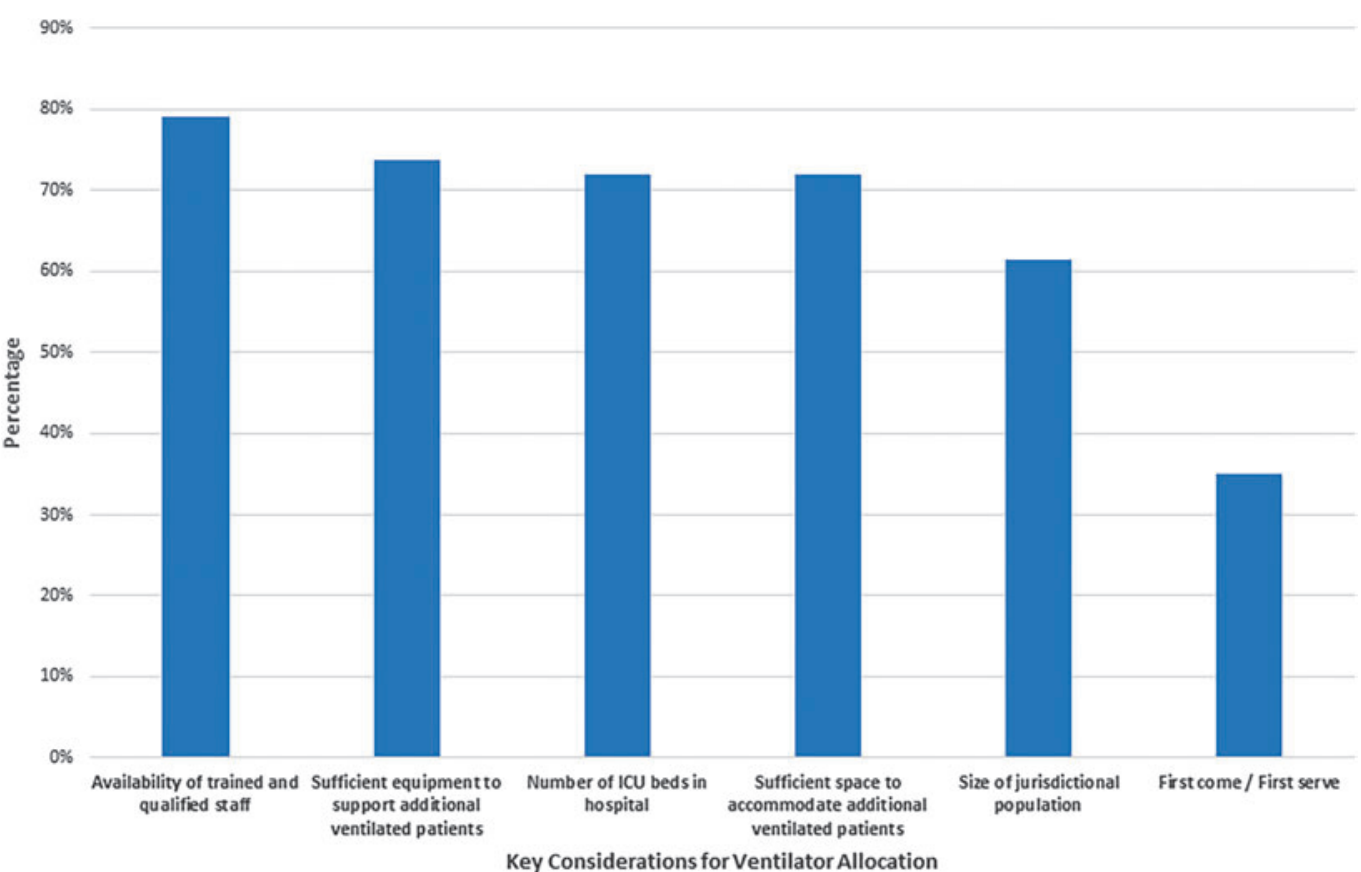

Figure 1. Percentage of Jurisdictions Citing Key Considerations for Ventilator Allocation, United States, $2015(n=57)$

patients (eg, oxygen, suctioning, airway management, monitoring equipment). ${ }^{3,6}$

As part of a conceptual framework for allocating federally stockpiled ventilators during a large-scale public health emergency, Figure 2 illustrates the steps in planning and allocating ventilators during a pandemic emergency. ${ }^{6}$ The strategies in this document focus on Step E_- "States determine allocation to individual hospitals" — and provide information to operationalize these concepts. By applying ethical principles throughout the process of pre-pandemic planning and allocation of ventilators during a pandemic, states can, in an equitable and transparent way, allocate scarce resources.

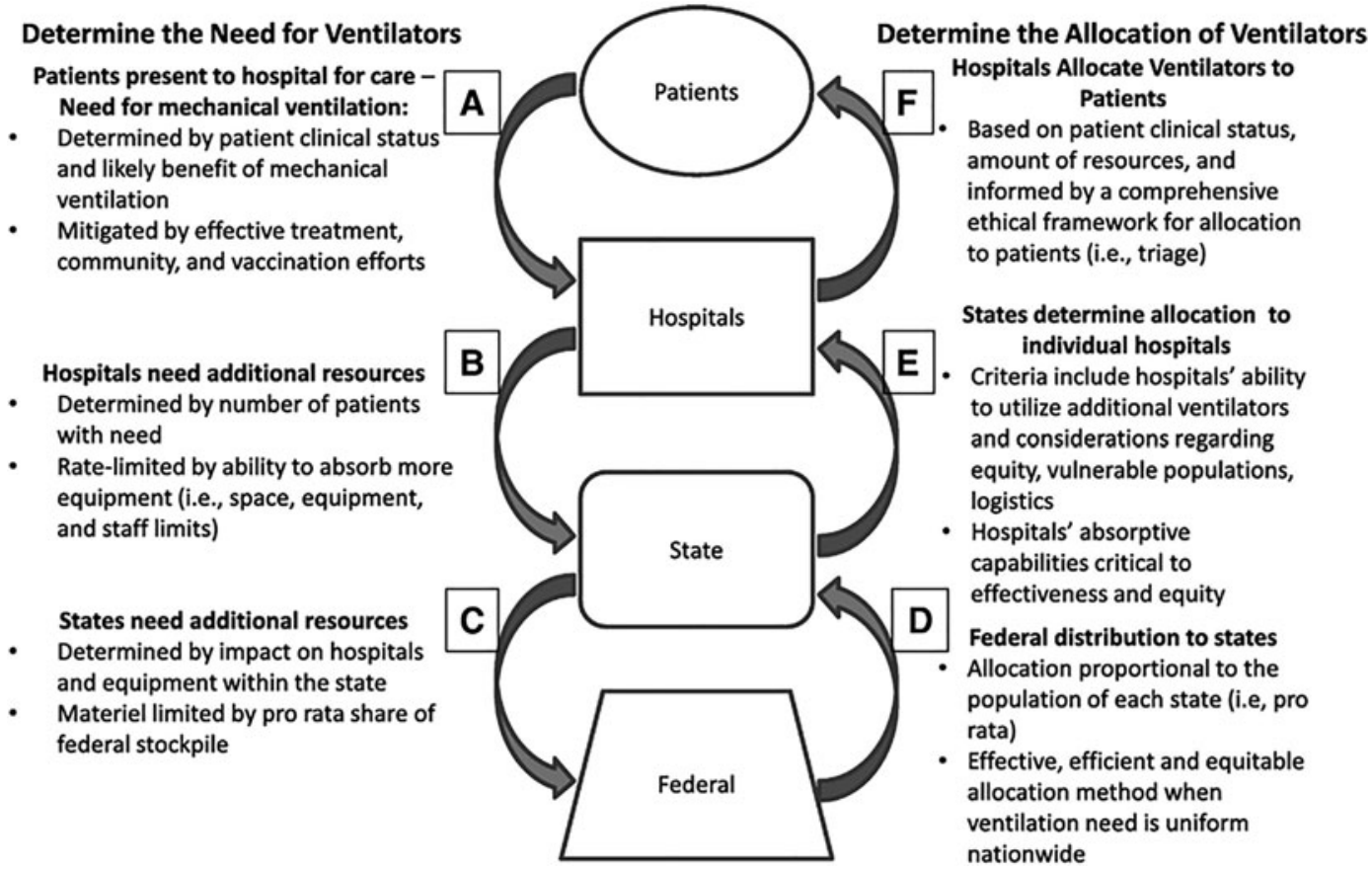

Figure 2. Conceptual Framework for Determining Need for and Allocation of Ventilators During a Public Health Emergency Graphic used with permission from Zaza et al. ${ }^{6}$ 


\section{Ethical Principles to Inform}

Allocation

CDC has developed guidance on ethical principles for use of ventilators during a pandemic, which includes as a main principle the "duty to plan." 13 These principles necessitate multiple preparedness efforts, including planning at state, local, and facility levels. A number of articles have been published describing recommended ethical and clinical principles for triaging and allocating ventilators to individual patients. ${ }^{10,13-16}$ In addition to surveillance and epidemiologic data, the same ethical principles relevant to allocating ventilators to individuals during times of scarcity can also inform decisions about how to allocate ventilators to facilities. In a pandemic, if resources are scarce, plans and protocols will need to shift from an individual patient care outcome perspective to a population-based focus and must be grounded in a principled allocation of resources that attempts to ensure equity and fairness.

Specific ethical principles can inform a jurisdiction's plans for allocation of ventilators. ${ }^{15}$ These include:

- Duty to plan: As previously mentioned, public health officials have a duty to prepare for allocating stockpiled ventilators in the face of scarcity. However, it may not be possible to develop a plan that will meet all patients' needs in future scenarios. ${ }^{13}$

- Transparency: State and local planners should share planning guidelines with hospitals and other facilities, partners, and stakeholders and seek public comment and incorporate public values into planning efforts. ${ }^{17}$ Public health officials should prepare to explain to the public the rationale and purpose of ventilator allocation decisions.

- Distributive justice: During an emergency when there are insufficient services and/or equipment to meet the needs of all, efforts should be focused on allocation to facilities that can save the greatest number of lives. Balancing distributive fairness and efficiency is extremely difficult even with advance planning. ${ }^{10,14,18}$

- Duty to care: Once a provider-patient relationship is formed, providers have the obligation to care for their patients, and the care they provide should be aligned with what a "reasonable physician" would provide under the circumstances during an emergency. ${ }^{15}$ If ventilators are insufficient to meet the needs of all those who would benefit from them, then plans should include other means of providing curative and palliative care for these patients. ${ }^{14}$ Healthcare facilities in a community that collaborate using a "systems approach" to plan for a pandemic may be able to develop community-level plans that designate specific facilities for patient care during a pandemic to improve outcomes. $^{19}$

- Duty to steward resources: Allocation consideration should include sending limited resources, like venti- lators, to facilities that can make the best use of the equipment. ${ }^{6}$

- Equity: To achieve fairness, the same allocation framework should be used to allocate stockpiled ventilators to all facilities in a jurisdiction, taking into consideration facilities' needs and available supply. The concepts of equity and consideration for vulnerable populations should be included in ventilator allocation plans.

\section{Pre-Pandemic Planning for Stockpiled Ventilator Allocation}

As a part of pandemic preparedness, public health officials should identify and query healthcare facilities in their jurisdiction that care for critically ill patients on mechanical ventilation to learn about their current inventory of these devices and their ability to absorb additional ventilators. Information about the types of patient populations served (including facilities' ability to care for critically ill neonatal and pediatric patients and adults including pregnant patients) should be collected. Healthcare coalitions that work with these facilities may be able to assist public health partners in conducting these assessments and coordinating system-level collaboration in a jurisdiction. ${ }^{19}$ To familiarize facilities and their staff, pre-pandemic training and discussions about use of specific models of stockpiled ventilators and ventilator allocation scenarios can be conducted.

Draft plans can be developed to serve as a starting point when need arises. Planning should incorporate stakeholder and public input based on scenarios in which there are insufficient ventilators, staff, and ancillary supplies during a time of critical need during a pandemic. The principles of crisis standards of care should be incorporated in planning and decision making. ${ }^{20}$ Allocation decisions must be made carefully because reallocation will be difficult once ventilators have been distributed. One modeling study of ventilator stockpiling dynamics in a large state found that the peak of the pandemic would likely affect different areas of the state almost simultaneously, making redistribution of ventilators challenging. ${ }^{8}$

\section{Considerations for Ventilator Allocation}

At the time of an event, verifying information previously gathered about facilities' needs and capacity to absorb additional ventilators will be critical. Allocation of stockpiled ventilators may include acute care hospitals or other settings such as long-term care facilities. ${ }^{21}$ These allocation decisions will likely need input from state and local leaders and legal and ethical experts, as well as engaged and informed community stakeholders. In summary, decisions on how to 


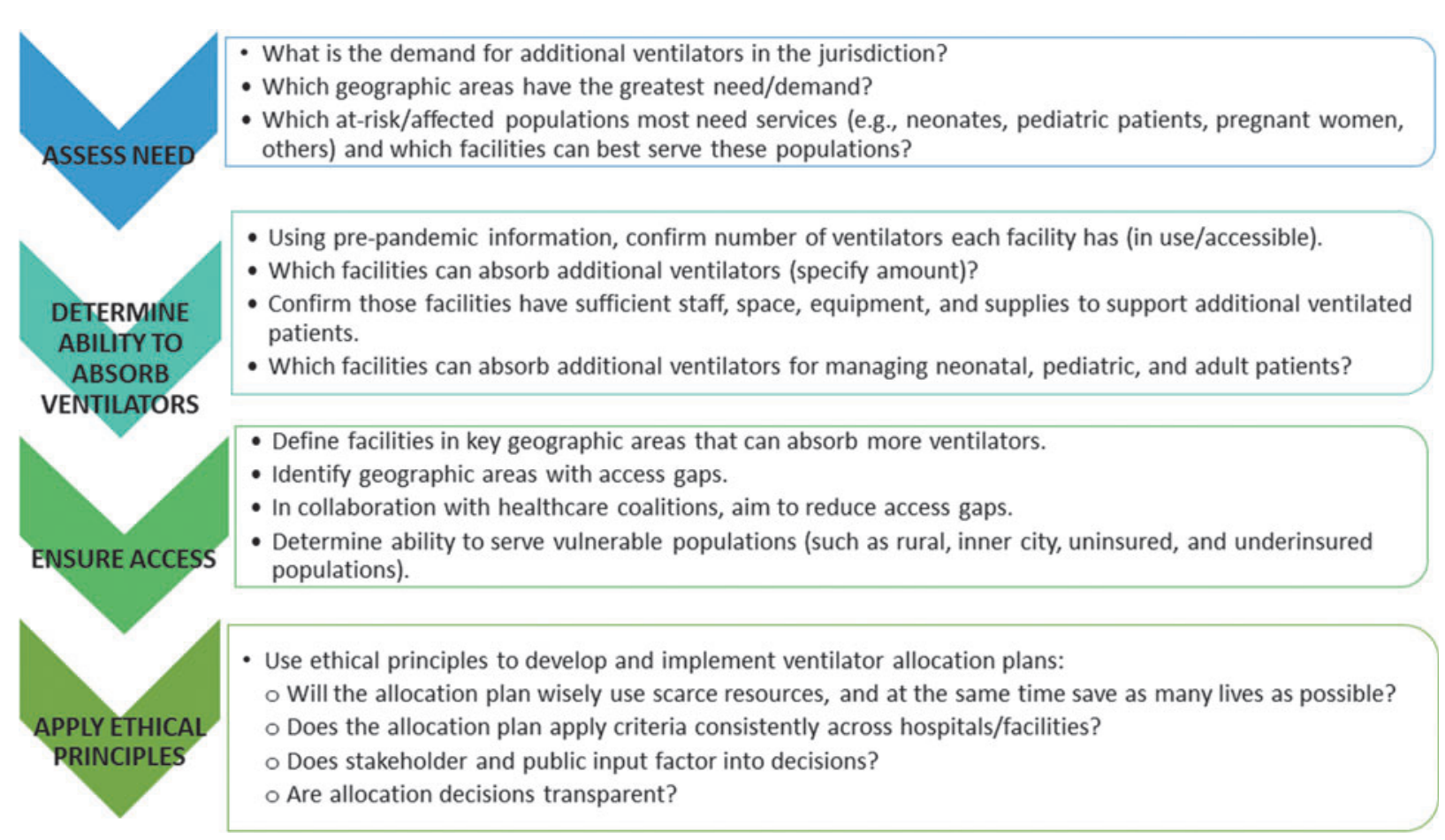

Figure 3. Key Factors to Consider When Determining Where to Allocate Ventilators During a Pandemic

allocate ventilators during a pandemic response should be informed by the following factors (see Figure 3):

- Assessment of need: During a response, jurisdictions must assess demand and need for ventilators based on available surveillance data (eg, the number of patients with respiratory failure resulting from infection who currently need and will benefit from mechanical ventilation). Assessment should factor in the number of ventilators currently available for use by each facility, including any additional ventilators to which the facility may have access (eg, cached equipment, ventilator surge contracts, sharing agreements).

- Determination of ability to absorb additional ventilators: Jurisdictions must confirm and assess any available information on each facility's ability to absorb and use additional ventilators to care for critically ill patients and quantify the number of additional ventilators each facility can realistically absorb. This estimate should be based on having enough trained and qualified staff, adequate space, and necessary equipment needed for caring for additional patients on mechanical ventilation.

- Ensuring access to ventilators for vulnerable or highrisk populations: This element refers to the geographic location or catchment area served by the facility within the jurisdiction and/or the ability to serve vulnerable and high-risk populations within this area.

- Consider whether each facility serves as a referral hospital or regional hospital or serves a high- density population area, rural area, or underserved populations.

- Determine how to distribute a limited supply of ventilators to serve the largest number of people at risk or in need.

- Following ethical principles: Use ethical principles to guide the development and implementation of ventilator allocation plans. Examples of questions to consider include:

- Will the allocation plan use scarce resources in a manner to save as many lives as possible?

- Does the allocation plan apply criteria consistently across all hospitals and facilities?

o If ventilators are insufficient to meet the needs of all those who would benefit from them, what are plans for providing care for patients who cannot access them?

- How do stakeholder and public input and values factor into decisions?

- Are allocation decisions transparent?

\section{Conclusions}

The strategies portrayed in Figure 3 are designed to assist planners in preparedness and allocation of ventilators during a pandemic. Ideally, planning ahead would provide jurisdictions with a baseline assessment of the ability of healthcare facilities in their jurisdiction to absorb and deploy additional supplies of ventilators. At the time of a 
pandemic response, the impact of disease (severity of illness, transmission), the effectiveness of mechanical ventilation at preserving life given the specific pandemic pathogen, and the population subgroups most affected who may need mechanical ventilation will all factor into allocation decisions. Using ethical principles to assess need, determine ability to absorb additional ventilators, and ensure resources to the most vulnerable populations, state and local public health officials can equitably allocate stockpiled ventilators during a pandemic. Having strategies for allocating scarce resources like ventilators in advance may improve decision making, with the understanding that plans will need to adapt to the realities presented during a pandemic response.

\section{REFERENCES}

1. Rubinson L, Vaughn F, Nelson S, et al. Mechanical ventilators in US acute care hospitals. Disaster Med Public Health Prep 2010;4(3):199-206.

2. Meltzer MI, Patel A, Ajao A, Nystrom SV, Koonin LM. Estimates of the demand for mechanical ventilation in the United States during an influenza pandemic. Clin Infect Dis 2015;60(Suppl 1):S52-S57.

3. Ajao A, Nystrom SV, Koonin LM, et al. Assessing the capacity of the US health care system to use additional mechanical ventilators during a large-scale public health emergency. Disaster Med Public Health Prep 2015;9(6):634641.

4. Wallace DJ, Seymour CW, Kahn JM. Hospital-level changes in adult ICU bed supply in the United States. Crit Care Med 2017;45(1):e67-e76.

5. University of North Carolina at Chapel Hill. Cecil G. Sheps Center for Health Services Research. 168 rural hospital closures: January 2005 - Present (126 since 2010). https:// www.shepscenter.unc.edu/programs-projects/rural-health/ rural-hospital-closures/. Accessed March 12, 2020.

6. Zaza S, Koonin LM, Ajao A, et al. A conceptual framework for allocation of federally stockpiled ventilators during largescale public health emergencies. Health Secur 2016;14(1): $1-6$.

7. Wilgis J. Strategies for providing mechanical ventilation in a mass casualty incident: distribution versus stockpiling. Respir Care 2008;53(1):96-103.

8. Huang H-C, Araz OM, Morton DP, et al. Stockpiling ventilators for influenza pandemics. Emerg Infect Dis 2017; 23(6):914-921.

9. Malatino EM. Strategic national stockpile: overview and ventilator assets. Respir Care 2008;53(1):91-95.

10. Hick JL, Rubinson L, O'Laughlin DT, Farmer JC. Clinical review: allocating ventilators during large-scale disastersproblems, planning, and process. Crit Care 2007;11(3):217.

11. Meltzer MI, Patel A. Stockpiling ventilators for influenza pandemics. Emerg Infect Dis 2017;23(6):1021-1022.
12. Courtney B, Hodge JG Jr, Toner ES, et al. Legal preparedness: care of the critically ill and injured during pandemics and disasters: CHEST consensus statement. Chest 2014;146(4 Suppl):e134S-144S.

13. Centers for Disease Control and Prevention; Ventilator Document Workgroup, Ethics Subcommittee of the Advisory Committee to the Director. Ethical considerations for decision making regarding allocation of mechanical ventilators during a severe influenza pandemic or other public health emergency. Atlanta, GA: CDC; 2011. https://www. cdc.gov/about/advisory/pdf/VentDocument_Release.pdf. Accessed March 17, 2020.

14. Biddison LD, Berkowitz KA, Courtney B, et al. Ethical considerations: care of the critically ill and injured during pandemics and disasters: CHEST consensus statement. Chest 2014;146(4 Suppl):e145S-155S.

15. Powell T, Christ KC, Birkhead GS. Allocation of ventilators in a public health disaster. Disaster Med Public Health Prep 2008;2(1):20-26.

16. Silva DS, Gibson JL, Robertson A, et al. Priority setting of ICU resources in an influenza pandemic: a qualitative study of the Canadian public's perspectives. BMC Public Health 2012;12(1):241.

17. Patrone D, Resnik D. Pandemic ventilator rationing and appeals processes. Health Care Anal 2011;19(2):165-179.

18. White DB, Katz MH, Luce JM, Lo B. Who should receive life support during a public health emergency? Using ethical principles to improve allocation decisions. Ann Intern Med 2009;150(2):132-138.

19. Dichter JR, Kanter RK, Dries D, et al. System-level planning, coordination, and communication: care of the critically ill and injured during pandemics and disasters: CHEST consensus statement. Chest 2014;146(4 Suppl):e87S-102S.

20. Institute of Medicine; Board on Health Sciences Policy; Committee on Guidance for Establishing Standards of Care for Use in Disaster Situations; Altevogt B, Stroud C, Hanson SL, Hanfling D, Gostin LO, eds. Guidance for Establishing Crisis Standards of Care for Use in Disaster Situations: A Letter Report. Washington DC: National Academies Press; 2009.

21. Macintyre N. Mechanical ventilation. In: Broaddus V, Ernst J, King Jr T, Lazarus S, eds. Murray and Nadel's Textbook of Respiratory Medicine. 6th ed. New York: Elsevier; 2016.

Manuscript received March 13, 2020; accepted for publication March 17, 2020.

Address correspondence to: Lisa M. Koonin, DrPH, MN, MPH Centers for Disease Control and Prevention 1600 Clifton Road, NE Mailstop H24-8 Atlanta, GA 30329

Email:1mk1@cdc.gov 